\title{
Effects of Predicted Reduced Summer Rainfall on Growth and Development of Silver Birch (Betula Pendula Roth) and Downy Birch (Betula pubescens Ehrh)
}

\author{
Dhirendra Kumar Pradhan', Christine Cahalan² and Sunita Ulak ${ }^{3}$
}

\begin{abstract}
Climate is one of the major factors that govern the distribution of tree species. Climate change has already affected the growth, structure and distribution of trees and woodlands. Global climate change projections are wetter winters, drier summers and significance changes in temperature regimes in the next few decades. The main objective of this study was to experimentally demonstrate the effects of decline in summer rainfall, as predicted by UKCP09/IPCC, on height and diameter growth in two co-occurring silver birch (Betula pendula Roth) and downy birch (Betula pubescens Ehrh) and provide further understanding of the changes in growth and development in response to a decrease in water availability. One-yearold seedlings were grown in a temperature-controlled greenhouse for eight weeks in a split-plot experimental design. Their height and diameter were measured and analyzed. Result showed that plant height and diameter was significantly reduced with increased water stress. B. pendula showed higher physiological traits indicating that this species can perform better than B. pubescensin water-deficit conditions.
\end{abstract}

Key Words: $B$. pendula, B. pubescens, height, diameter, climate change

Pradhan D. K., Cahalan C., Ulak S. (2018): Effects of Predicted Reduced Summer Rainfall on Growth and Development of Silver Birch (Betula Pendula Roth) and Downy Birch (Betula pubescens Ehrh). Forestry: Journal of Institute of Forestry, Nepal. No. 15: page 28 to 44.

\footnotetext{
${ }^{1}$ Government of Nepal, Ministry of Forests and Environment Author corresponding email address: dhirendrapradhan@hotmail.com

${ }^{2}$ University of Bangor, United Kingdom

${ }^{3}$ Government of Nepal, Ministry of Forests and Environment
} 


\section{Introduction}

It is an undeniable fact that the climate is changing and the Earth is warming at an unprecedented rate (IPCC 2007a). Global climate may change as a result of both natural and anthropogenic drivers, but it is highly likely that a large part of the warming in recent decades is due to human activities (Hulme et al. 2002; IPCC 2007b). Human activities are increasing the concentration of $\mathrm{CO}_{2}$ in atmosphere through fossil fuel burning, deforestation and forest degradation and are consequently causing global warming. Global climate change is the most serious and most difficult to manage environmental issue that has emerged in the past few decades (Desseler, Parson 2006).

Reduced summer rainfall, which is predicted in most parts of the earth, can cause drought effects on plants and increase mortality among young and newly established trees, top-dying of mature trees, decrease the quality and quantity of timber, and increase fire intensities. Reduced summer rainfall and increased temperature can cause longer periods of drought and increased evaporation will lead to longer periods of drought stress on trees. These impacts will be further exaggerated by other effects of rising $\mathrm{CO}_{2}$ in the atmosphere like longer growing seasons, increase in leaf surface area, and change in stomatal functioning that regulate water loss from leaves (Broadmeadow et al. 1999). Higher temperatures will prolong growing seasons and elevated $\mathrm{CO}_{2}$ will cause a $\mathrm{CO}_{2}$ fertilization effect; for example, a Forestry Commission, UK study showed that the growth of oak saplings (Quercus petraea) was enhanced by up to $175 \%$ in controlled elevated $\mathrm{CO}_{2}$ conditions. This may increase overall productivity of the forest but water availability due to reduced summer rainfall will be a limiting factor for tree growth (Broadmeadow 2000). This will create a stressful environment for the growth of trees and will have significant effects on their physiological performance (Epron, Dreyer 1993) and subsequently impacts on timber supply (Loustau et al. 2007). Most of insect pests that are affecting the forests are also benefiting from climate change because of reduced winter mortality (Murphy et al. 2009).

\section{Justification of the study}

Climate change means new challenges for forestry. There may be some opportunities to be gained from changing climate but the bulk of predicted climate change impacts are negative for our society and environment (Jenkins et al. 2009). 
The global climate has already changed in recent years and the impact of climate change can already be observed in forest and trees; impacts are predicted to be more severe in future climate situations (Read et al. 2009). Many countries including UK have predicted the future climate scenarios by using different models such as Global Climate Model. The UK Climate Projections (UKCP09) predicts the future climate of the UK under different emissions scenarios. UKCP09 uses three IPCC emissions scenarios, two of which come from the A1 story line, and one from the B1 storyline developed by the IPCC Special Report on Emissions Scenarios (SRES) (Jenkins et al. 2009). Within UKCP09 the emissions scenarios are classified based on relative greenhouse gas emission levels; high (SRES A1F1), medium (SRES A1B) and low (B1). According to UKCP09, by 2080 (relative to a 1961-90 baseline) under the medium emissions scenario central estimates for the Yorkshire and Humber region of the UK are that winter mean temperature will increase by $3^{\circ} \mathrm{C}$, summer mean temperature by $3.3^{\circ} \mathrm{C}$, summer mean daily maximum temperature by $4.3^{\circ} \mathrm{C}$, summer mean daily minimum temperature by $3.7^{\circ} \mathrm{C}$ and winter mean precipitation is by $15 \%$, while summer mean precipitation will decrease by $23 \%$ (Jenkins et al. 2009). These figures indicate that the climate in the UK will continue to warm throughout this century; as the climate changes, the tree species and woodland cover will change. As evident from the above figures, reduction in summer rainfall is likely to represent the most serious threat to woodland trees change and this will have serious impacts on drought sensitive species like B. pendula which suffer from drought-induced mortality; for example, after the severe droughts in 1976 and 2003 many B. pendula died in the UK (Forestry Commission 2011).

The changes in climatic patterns will have significant effects on the growth, physiology and development of trees, forests and woodlands. In addition, the native ranges of species will be changed leading to changes in species composition of forest communities; for example, the Forestry Commission (2011) reported that $B$. pubescens in the Yorkshire and Humber region under the 2050s high emissions and 2080s high emissions scenarios will not be suitable, and climatic condition for $B$. pendula will be marginal. This shows that climate change will have a significant effect on the distribution of species because a species which is suitable for a particular site in 2011 may not be suitable for the same site in the future. It means that climate change brings new challenges for forest conservation and development and particularly for the choice of species for planting on a particular site. 
It is clear that in the future, some native trees are likely to lose 'climate space'; their establishment will be unsuccessful and their space will be taken by other, possibly introduced species. Action to change the structure and composition of woodland is necessary to protect the forests so that they can perform social, ecological and economical functions in future efficiently (Kirby et al. 2005). In order to maintain the services that forests provide, a move towards planned action is desirable, given the long response times of trees and forests. It is essential to assess the suitability of particular species for particular locations to change forest composition and distribution to meet projected future climate and conditions and continue to provide the services that our society expects from forests.

Water plays an essential role in plant life. Most cellular process depends upon the cell water status of the plant, and therefore shortage of water leads to the malfunctioning of many vital metabolic processes (Roger 2001). Photosynthesis and gas exchange of leaves are affected by water stress due to stomatal closer and reduce rate of assimilation of $\mathrm{CO}_{2}$ per unit area of leaf. Water stress causes loss of cell turgor and reduces gas exchange and leaf elongation. Plants close their stomata to respond to conserve water loss from transpiration. So water stress causes a decrease in transpiration, and an increase in foliage temperature. Short-term exposure of plants to water stress enhances root respiration, whereas long-term exposure of plants to water stress gradually decreases respiration and is followed by a general decline in plant metabolic activities (Lambers et al. 1998). Farquhar et al. (1982) reported that biochemical capacity for photosynthesis and transpiration decreases as the water stress increases. Lack of sufficient water puts plants under water stress and makes them vulnerable to attack by several pests and diseases, for example, Biscogniauxia species which causes strip cankers on beech and oak are already observed in UK forests. Armillaria species attack and kill trees already weakened by biotic agents or abiotic factors such as drought (Gregory, Redfern 1998 cited in Read et al. 2009). Thus their potential to cause damage is expected to increase as trees suffer more frequent episodes of elevated temperatures and drought stress. Moreover, increase in temperature followed by reduction in rainfall results in lowering of the mortality of insect pests, and mass outbreaks of pest and diseases may then destroy the forest vegetation; for example, Elatobium abietinum and forest defoliators in the UK (Westgarth-Smith et al. 2007). 
Therefore, this study tries to determine how two different species of same genus, Betula pendula and Betula pubescens perform physically under simulated reduced summer rainfall conditions in a controlled environment and also to determine the quantitative effects of reduced rainfall on height, root collar diameter, biomass (dry weight of leaves, stem and roots), moisture content (stem, leaves and roots), shoot: root ratio and water deficit of B. pendula and B. pubescens.

\section{Materials and Methods}

\section{Site description}

\section{Tree species, watering treatments and experimental design}

The study was conducted in a fully temperature-controlled glasshouse at Henfaes Research Centre of the Bangor University, UK. One-year-old cell grown seedlings of $B$. pendula and B. pubescenswere used for the experiment. Four watering treatments were used. The amounts of water given in the different treatments were calculated from the summer (May, June, July) rainfall 2011 and UKCP09 predicted rainfall for the location Yorkshire Dales $(54.0928 \mathrm{~N},-2.1698 \mathrm{~W})$. The rainfall for the year 2011 for the region Yorkshire Dales was about $298 \mathrm{~mm}$. Based on IPCC Special Report on Emissions Scenarios, UKCP09 projected summer rainfall under the 2050s high emissions scenario (central estimate) is expected to be $241 \mathrm{~mm}$ (19\% reduction from the current rainfall), summer rainfall under the 2080s high emissions scenario (central estimate) is expected to be $214 \mathrm{~mm}$ (28\% reduction from the current rainfall) and summer rainfall under the 2080s high emissions scenario (10\% probability level) is expected to be $149 \mathrm{~mm}(50 \%$ reduction from the current rainfall).

The four watering treatments were:

$\mathrm{W}_{1}($ control $)=$ current rainfall

$\mathrm{W}_{2}=$ rainfall for 2050s high emissions scenario (central estimate)

$\mathrm{W}_{3}=$ rainfall for 2080s high emissions scenario (central estimate) and

$\mathrm{W}_{4}=$ rainfall for $2080 \mathrm{~s}$ high emissions scenario (10\% probability level)

Table 1: Water treatments used in the experiment

\begin{tabular}{|l|c|c|c|}
\hline Treatment & $\begin{array}{c}\text { Total summer } \\
\text { rainfall }(\mathbf{m m})\end{array}$ & $\begin{array}{c}\text { Amount/pot/day } \\
(\mathbf{m l})\end{array}$ & $\begin{array}{c}\text { Amount/pot/twice a } \\
\text { week (ml) }\end{array}$ \\
\hline $\mathbf{W}_{\mathbf{1}}$ & 298 & 43.1 & 150.8 \\
\hline $\mathbf{W}_{\mathbf{2}}$ & 241.38 & 34.9 & 122.2 \\
\hline $\mathbf{W}_{\mathbf{3}}$ & 214.56 & 31.0 & 108.5 \\
\hline $\mathbf{W}_{\mathbf{4}}$ & 149 & 21.5 & 75.3 \\
\hline
\end{tabular}


As suggested by Schwarz (2011) a split plot design was used for this experiment. Blocking was done to account for a temperature gradient from the entrance to the inner core of the green house. There were four blocks, four main plots (watering treatments), two sub-plots (species) and six plants per sub-plot.

Within each block four watering treatments (W1, W2, W3 and W4) were randomly assigned to the main plots. Within each main plot B. pendula $(\mathrm{SB})$ and B. pubescens (DB) were randomly assigned to the sub-plots as shown in Fig. 1. Overall, 192 potted seedlings (four blocks $\times$ four watering treatments $\times$ two species $\times$ six plants per sub-plot) were used.

\begin{tabular}{|c|c|c|c|}
\hline W2 & W3 & W4 & W1 \\
SB & DB & SB & DB \\
\hline W2 & W3 & W4 & W1 \\
DB & SB & DB & SB \\
\hline
\end{tabular}

Block-1

\begin{tabular}{|c|c|c|c|}
\hline W3 & W1 & W4 & W2 \\
DB & SB & DB & DB \\
\hline W3 & W1 & W4 & W2 \\
SB & DB & SB & SB \\
\hline
\end{tabular}

Block-III

\begin{tabular}{|c|c|c|c|}
\hline W2 & W4 & W1 & W3 \\
DB & SB & DB & SB \\
\hline W2 & W4 & W1 & W3 \\
SB & DB & SB & DB \\
\hline
\end{tabular}

Block-II

\begin{tabular}{|c|c|c|c|}
\hline W3 & W1 & W2 & W4 \\
SB & DB & SB & DB \\
\hline W3 & W1 & W2 & W4 \\
DB & SB & SB & SB \\
\hline
\end{tabular}

Block-IV

Wi: Water regime, SB: B. pendula, DB: B. pubescens

Fig. 1: Randomized allocations of watering treatments and species in the split-plot design

\section{Management of the experiment and measurements}

The plants were fully watered for about three weeks before the start of watering treatments to acclimatize them to their new environment. The surface of the pots was covered with plastic held in place by elastic bands to minimize the loss of water from evaporation. After the experiment started, the plants were watered twice a week with the amount of water shown in Table 1. Insecticide was sprayed once in the middle ( $3^{\text {rd }}$ week) of the experiment to control the aphids. 


\section{Measurement of height and diameter}

Heights of the all plants (192) were measured at the beginning of the experiment. There was a significant difference in the starting height between species, and it was therefore used as a covariate in the analysis of height and other data. Subsequently, heights were measured at two-week intervals until the end of the experiment. Height from soil surface to the tip of the terminal bud on the leading stem was measured to the nearest $0.1 \mathrm{~cm}$. Heights were measured six times throughout the experiment as indicated below:

$\mathrm{Hi}=$ initial height

$\mathrm{H} 0=$ starting height

$\mathrm{H} 1=$ height after two weeks

$\mathrm{H} 2$ = height after four weeks

$\mathrm{H} 3$ = height after six weeks

$\mathrm{H} 4$ = height at the end

Relative height growth over the research period was calculated by using the formula RHGR $(\%)=100 \times($ End height - Start height $) /$ Start height

\section{Diameter}

Root collar diameter was measured by digital callipers at a fixed point marked at the beginning of the experiment at $2 \mathrm{~cm}$ above the soil surface. Like height, diameter was measured at two-week intervals to the nearest $0.01 \mathrm{~mm}$ until the end of the experiment. Diameter was measured five times throughout the experiment as indicated below:

$\mathrm{D} 0=$ starting diameter

D1 = diameter after two weeks

D2 = diameter after four weeks

D3 = diameter after six weeks

D4 = diameter at the end

Relative diameter increment (RDIGR) over the research period was calculated by using the formula: RDIGR $(\%)=100 \times($ End diameter - Start diameter $) /$ Start diameter

\section{Data analysis}

The data were analyzed using MINITAB ${ }^{\circledR}$ statistical software version 15. Data which were not normally distributed was transformed by using $\log 10$ transformation 
functions. Depending on the data type two-way analysis of variance (ANOVA) or analysis of covariance (ANCOVA) were used. For final height, diameter, the starting size of the plant was used as a covariate. When significant differences were detected by the ANCOVA or ANOVA, pair wise mean comparisons (Bonferroni) were done to compare the treatment means. Unless otherwise mentioned the $95 \%$ confidence interval was used to test the significance of differences.

\section{Results and Discussion}

\section{Height and diameter}

Starting heights (H0) of the two species were significantly different (Table 2). The effect of watering treatment on height growth was significant in the sixth and eighth weeks of the experiment and a significant interaction between treatment and species was found from the second week onwards. The effect of block was not significant at any time, and the three way interaction between block, treatment and species was only significant in the fourth week.

Table 2: Results of analysis of variance of starting height and analysis of covariance of height after two, four, six and eight weeks (final height) of $B$. pendula and $B$. pubescens under four watering regimes.

\begin{tabular}{|l|c|c|c|c|c|c|c|}
\hline \multicolumn{1}{|c|}{ Height } & Block & Treatment & Species & $\begin{array}{c}\text { Block } \times \\
\text { species }\end{array}$ & $\begin{array}{c}\text { Block } \times \\
\text { treatment }\end{array}$ & $\begin{array}{c}\text { Treatment } \\
\times \text { species }\end{array}$ & $\begin{array}{c}\text { Block } \times \text { treatment } \\
\times \text { species }\end{array}$ \\
\hline Start (HT0) & NS & NS & $* *$ & NS & NS & NS & NS \\
\hline $2^{\text {nd }}$ week (HT1) & NS & NS & NS & NS & NS & $*$ & NS \\
\hline $4^{\text {th }}$ week (HT2) & NS & NS & NS & $*$ & NS & $*$ & $*$ \\
\hline $6^{\text {th }}$ week (HT3) & NS & $* *$ & $*$ & $*$ & $*$ & $* *$ & NS \\
\hline $8^{\text {th }}$ week (HT4) & NS & $* *$ & $* *$ & NS & $*$ & $* *$ & NS \\
\hline
\end{tabular}

NS: not significant; *: significant at $\mathrm{p} \leq 0.05 ; * *$ : significant at $\mathrm{p} \leq 0.01$

Relative height growth was significantly different among treatments and between species. Mean relative height growth (\%) was higher in B. pubescens $(8.22 \pm 6.27)$ than in B. pendula (7.41 \pm 9.40 ; Fig. 2). Relative height growth in treatment W1 was significantly different from that in treatments W2, W3 and W4 (Table 3). The growth curve in Fig. 3 shows that there was rapid growth in height of both species between initial measurement and the start of the experiment, which can be attributed to free watering before the experiment. After the start of the experiment height growth was slower, indicating the effect of treatments on height growth. 
Table 3: Matrix of pairwise comparisons (Bonferroni test) of relative height growth between watering treatments

\begin{tabular}{|c|c|c|c|c|}
\hline & W1 & W2 & W3 & W4 \\
\hline W1 & & & & \\
\hline W2 & $*$ & & & \\
\hline W3 & $*$ & NS & & \\
\hline W4 & $*$ & NS & NS & \\
\hline
\end{tabular}

NS: not significant; *: significant at $\mathrm{p} \leq 0.05$
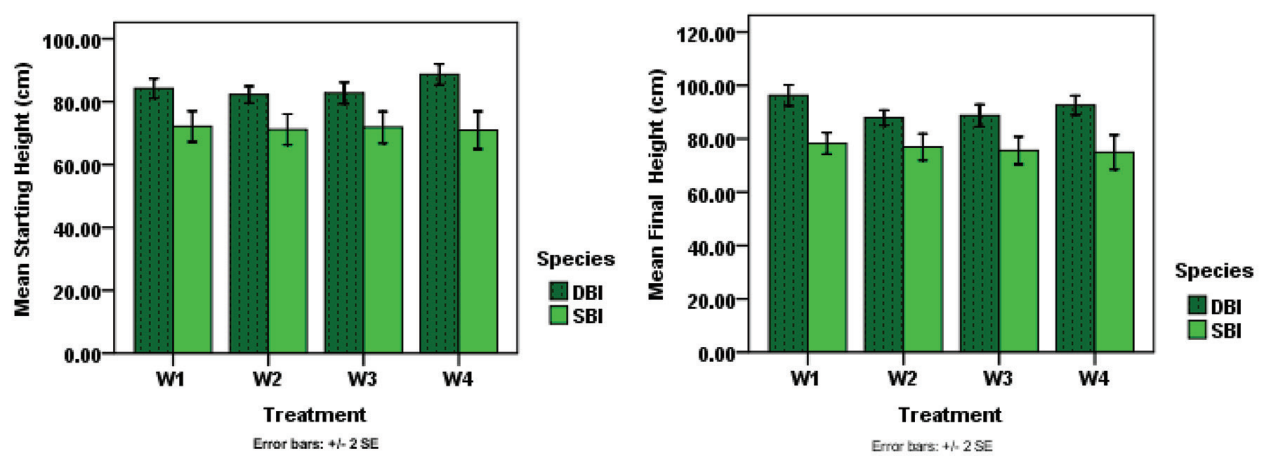

Fig. 2: Heights at the different stage of experiment: mean height at the start of the experiment (left) and mean height at the end of the experiment (right).
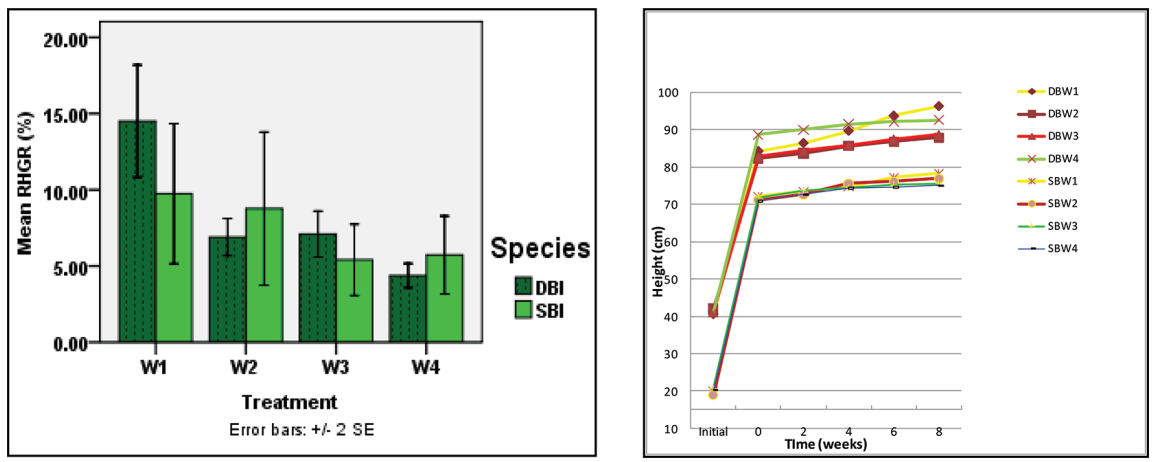

Fig. 3: (Left) Mean relative height growth rates at the end of the experiment relative to starting height. (Right) Growth curves of height for species and watering treatment combinations. Initial refers to the height at the time when the plants were brought from the nursery (i.e. height at the end of the 2010 growing season).

When one year old seedling of $B$. pendula and $B$. pubescens were brought from the nursery the mean height of $B$. pubescens $(41.21 \pm 3.9 \mathrm{~cm})$ was significantly 
greater than the mean height of $B$. pendula $(19.88 \pm 2.23 \mathrm{~cm})$. Their heights were also significantly different at the beginning of experiment. The effect of treatments on height growth was significant after the sixth week whereas effects on diameter were significant from the fourth week of the experiment. Significant interactions between species and treatment were observed after the second week indicating that treatments had different effects on the height growth of $B$. pendula and $B$. pubescens.

The general reduction in plant height and diameter with increase in water deficit (Fig. 3) in both species agrees with the results of Nielsen, Jorgensen (2003) and Tognetti et al. (1995). Nielsen, Jorgensen (2003) found that in Fagus sylvatica diameter and height growth reduced with increasing water stress. They found that root collar diameter reduced by $43 \%$ in the drought-treated seedlings compared to well-watered seedlings and the corresponding reduction in the height was 53\%. However, Sanchez-Gomez et al. (2006) argued that water stress has little impact on relative height growth but a major impact on relative diameter growth.

In the present study, the two species had significantly different relative height growth rates under different emissions scenarios. Mean relative height growth rate in B. pubescens decreased in the sequence $\mathrm{W} 1>\mathrm{W} 3>\mathrm{W} 2>\mathrm{W} 4$; for $B$. pendula the sequence was $\mathrm{W} 1>\mathrm{W} 2>\mathrm{W} 4>\mathrm{W} 3$ and over all species and treatment combinations it was $\mathrm{W} 1>\mathrm{W} 2>\mathrm{W} 3>\mathrm{W} 4$. For $B$. pubescens mean relative height growth was inexplicably higher in treatment W3 than in treatment W2, but the difference was statistically not significant. Likewise, for $B$. pendula mean relative height growth was inexplicably higher in W4 than in treatment W3, but this difference was also statistically not significant. These results suggest that as water stress increased height growth rate decreased. Water availability is a crucial factor that determines diameter and height increment in plants (Koch et al. 2004). Cotillas et al. (2009) reported that in mediterranean oak forest, a reduction in rainfall of up to $15 \%$ resulted in a decrease of height growth rate of Quercus cerrioides by $20 \%$. The authors also suggested that the effect on height growth is a species-specific response.

Compared with the mean relative height growth rate of the control treatment (W1), $19 \%$ reduction in summer precipitation, height increment of $B$. pendula and $B$. pubescens reduced by $10 \%$ and $52 \%$ respectively, and under a $28 \%$ reduction in 
summer rainfall, height growth reduced by $44 \%$ and $51 \%$ respectively. Similarly, under a $50 \%$ reduction in summer rainfall from the current value, the height increment of B. pendula and B. pubescens reduced by $41 \%$ and $70 \%$ respectively. This shows that height growth of $B$. pendula was comparatively less affected than that of $B$. pubescens by predicted reductions in summer rainfall. However, the results also showed that reductions in summer rainfall as predicted by UKCOP09 will have severe consequences for the height growth of both species.

\section{Diameter growth}

There was no significant difference in diameter between B. pendula and B. pubescens before the start of the experiment. A significant effect of watering treatments on diameter increment was observed from the fourth week of the experiment onwards. Similarly, a significant three way interaction between block, treatment and species was found from the fourth week of the experiment onwards. No significant difference between species was found throughout the experiment (Table 4).

Table 4: Results of analysis of variance of starting diameter and analysis of covariance of diameter after two, four, six and eight weeks (final diameter) of $B$. pendula and $B$. pubescens under four watering regimes.

\begin{tabular}{|c|c|c|c|c|c|c|c|}
\hline $\begin{array}{c}\text { Diameter } \\
\text { (Week) }\end{array}$ & Block & Treatment & Species & $\begin{array}{c}\text { Block } \times \\
\text { Species }\end{array}$ & $\begin{array}{c}\text { Block } \times \\
\text { Treatment }\end{array}$ & $\begin{array}{c}\text { Treatment } \\
\times \text { Species }\end{array}$ & $\begin{array}{c}\text { Block } \times \\
\text { Treatment } \\
\times \text { species }\end{array}$ \\
\hline Start (D0) & NS & NS & NS & NS & NS & NS & NS \\
\hline $2^{\text {nd }}$ week (D1) & NS & NS & NS & NS & NS & NS & NS \\
\hline $4^{\text {th }}$ week (D2) & NS & $* *$ & NS & NS & NS & NS & $*$ \\
\hline $6^{\text {th }}$ week (D3) & NS & $* *$ & NS & NS & NS & NS & $*$ \\
\hline $8^{\text {th }}$ week (D4) & NS & $* *$ & NS & NS & NS & NS & $*$ \\
\hline
\end{tabular}

NS: not significant; *: significant at $\mathrm{p} \leq 0.05 ; * *$ : significant at $\mathrm{p} \leq 0.01$

Mean relative diameter growth was higher in $B$. pendula $(19.89 \pm 12.34)$ than in $B$. pubescens (17.19 \pm 9.54 ; Fig. 4). Mean relative diameter growth in treatment W1 was significantly different from that in treatments W2 and W4; and treatment W3 was significantly different from treatment W4 (Table 5). The diameter growth curve in Fig. 5 shows that there was slow diameter increment after the start of watering treatments. 
Table 5: Matrix of pairwise comparisons (Bonferroni test) of relative diameter growth between watering treatments

\begin{tabular}{|c|c|c|c|c|}
\hline & W1 & W2 & W3 & W4 \\
\hline W1 & & & & \\
\hline W2 & $*$ & & & \\
\hline W3 & NS & NS & & \\
\hline W4 & $*$ & NS & $*$ & \\
\hline
\end{tabular}

NS: not significant; *: significant at $\mathrm{p} \leq 0.05$
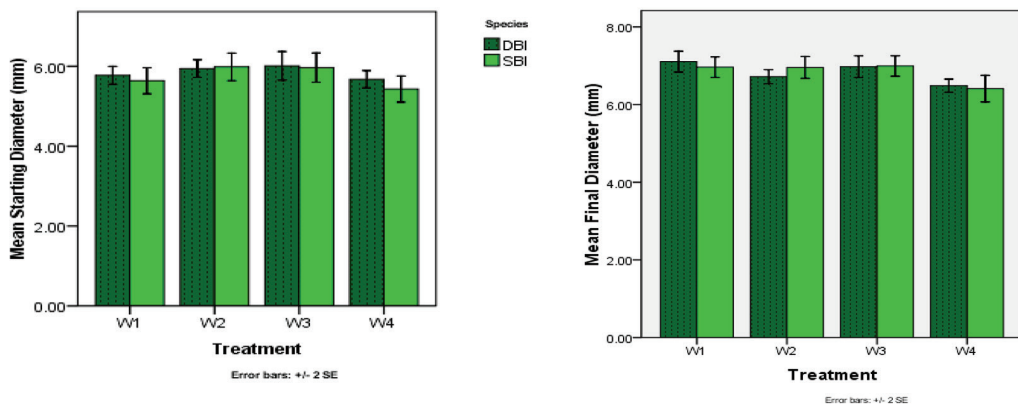

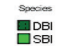

Fig. 4: Diameter at the different stage of experiment: (A) mean diameter at the start of the experiment and (B) mean diameter at the end of theexperiment.
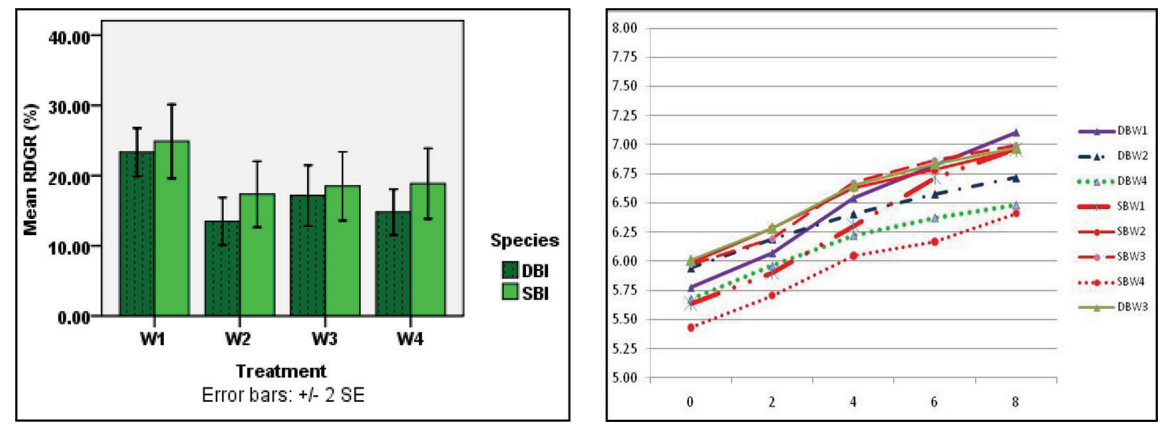

Fig. 5: (left) Mean relative diameter growths at the end of the experiment relative to diameter at the start of the experiment. (Right) Growth curves of diameter for species and watering treatment combinations. Initial refers to the diameter at the time when the plants were brought from the nursery (i.e. height at the end of the 2010 growing season). 
Table 6: Pearson correlation coefficient and $\mathrm{p}$ value between diameter and height throughout the experiment. DMi refers to diameter and HTi to height.

\begin{tabular}{|c|c|c|c|c|c|}
\hline Variables & HT0 & HT1 & HT2 & HT3 & HT4 \\
\hline DM0 & $\begin{array}{c}0.388 \\
<0.0005\end{array}$ & & & & \\
\hline DM1 & & $\begin{array}{c}0.421 \\
<0.0005\end{array}$ & & & \\
\hline DM2 & & & $\begin{array}{c}0.416 \\
<0.0005\end{array}$ & & \\
\hline DM3 & & & & $\begin{array}{c}0.387 \\
<0.0005\end{array}$ & \\
\hline DM4 & & & & & 0.349 \\
& & & & & $<0.0005$ \\
\hline
\end{tabular}

The correlation between height and diameter was calculated for all the measurement dates. There was a medium (all $\mathrm{r}<0.5$ ) but significant (all $p$ values $\leq 0.0005$ ) correlation between diameter and height throughout the experiment (Table 6).

There was no significant difference in diameter growth between the species throughout the experimental period. The relative diameter growth rate decreased as the duration of water stress increased. After the fourth week differences among the treatments were highly significant and remained so until the end of the experiment. These results are in general agreement with the studies conducted with other tree species such as Quercus species and Arbutus unedo by Ogaya, Penuelas (2007). They found that in holm oak, stem diameter increment is highly and positively correlated with annual rainfall, and that drought significantly reduced diameter increment of Quercus ilex by $41 \%$ and of Arbutus unedo by $63 \%$ when a drought experiment was conducted for five years by reducing soil water availability to about $15 \%$ of that of the control. In contrast, Cotillas et al. (2009) reported that a reduction in rainfall had no significant effect on stem and stump basal area in the mediterranean oak forest.

The control treatment (W1) had higher relative diameter growth than treatments W2, W3 and W4. Compared with the mean relative diameter growth rate of the control treatment $\mathrm{W} 1$, under a 19\% reduction in summer precipitation (as predicted for the 2050s high emissions scenario, central estimate) the diameter increment of B. pendula and B. pubescens reduced by $30 \%$ and $42 \%$ respectively. Under a $28 \%$ 
reduction of summer precipitation from the current value the diameter increment of B. pendula and B. pubescens reduced by $31 \%$ and $42 \%$ respectively. Similarly, under a $50 \%$ reduction in summer rainfall from the current value, the diameter increment of B. pendula and B. pubescens reduced by $25 \%$ and $37 \%$ respectively. This shows that growth of $B$. pendula is comparatively better in reduced rainfall situations.

Mean relative diameter growth rate in B. pubescens, B. pendula and all species and treatment combinations decreased in the sequence $\mathrm{W} 1>\mathrm{W} 2>\mathrm{W} 3>\mathrm{W} 4$.

\section{Conclusion}

Reduction in summer rainfall significantly increased the water deficit in plants. Height and diameter growth of $B$. pendula and B. pubescens were reduced significantly. The effect on height growth was more pronounced for $B$. pubescens. Under the 2080s high emissions scenario (the extreme water stressed treatment), results showed that height and diameter growth in B. pubescens can be reduced up to $70 \%$ and $37 \%$ respectively. Similar effects were observed for height and diameter growth in B. pendula. The height and diameter growth were reduced by $41 \%$ and $25 \%$ respectively.

The study showed that water deficit situations created due to reduction in summer rainfall have significant effects on plant growth. Higher height and diameter growth in B. pendula showed that the species can perform better than B. pubescens in future climate change scenarios. 


\section{Literature Cited}

Broadmeadow M. (2000): Climate Change - Implications for Forestry in Britain, Forestry Commission Information note, 231 Corstorphine Road, Edinburgh.

Broadmeadow M. S. J., Heath J., Andrandle T. J. (1999): Environmental limitations to $\mathrm{O}_{3}$ uptake - some key results from young trees growing at elevated $\mathrm{CO}_{2}$ concentrations. Water, Air and Soil Pollution 116, 299-310.

Cotillas M., Sabate S., Gracia C., Espelata J. M. (2009): Growth response of mixed mediterranean oak coppices to rainfall reduction.Could selective thinning have any influence on it? Forest Ecology and Management 258: 1677-1683.

Desseler A. E., Parson E. A. (2006): The science and politics of global climate change; a guide to the debate. Cambridge University Press, Cambridge.

Epron D., Dreyer E. (1993): Photosynthesis of oak leaves under water-stress

- maintenance of high photochemical efficiency of photosystem-ii and occurrence of non uniform $\mathrm{CO}_{2}$ assimilation. Tree Physiology 13.

Farquhar G. D., Sharkey T. D. (1982): Stomatal Conductance and Photosynthesis. Anr. Rev. Plant Physiol. 1982. 33:317-45

Forestry Commission (2011): Tree species suitability in a future climate in Yorkshire and Humber region. Available at: http://www.forestry.gov.uk/website/ forestresearch.nsf/ ByUnique/INFD-84PEJ8, accessed 14 $4^{\text {th }}$ April, 2011 and $9^{\text {th }}$ September 2017.

Hulme M., Jenkins G., Lu X. (2002): Climate change scenarios for the United Kingdom: the UKCIP02 Scientific Report. Tyndall Centre, University of East Anglia, Norwich, UK.

Intergovernmental Panel on Climate Change (2007a): Climate Change 2007: The Physical Science Basis. Contribution of Working Group I to the Fourth Assessment Report of the Intergovernmental Panel on Climate Change [Solomon, S., D. Qin, M. Manning, Z. Chen, M. Marquis, K.B. Averyt, M.Tignor and H.L. Miller (eds.)]. Cambridge University Press, Cambridge, United Kingdom and New York, USA.

Intergovernmental Panel on Climate Change (2007b): Climate Change 2007: Synthesis Report. Contribution of Working Groups I, II and III to the Fourth Assessment Report of the Intergovernmental Panel on Climate Change [Core Writing Team, Pachauri, R. K. and Reisinger, A. (eds.)]. IPCC, Geneva, 
Switzerland.

Jenkins G. J., Murphy J. M., Sexton D.S., Lowe J. A., Jones P., Kilsby C. G. (2009):

UK climate projections: briefing report. Met Office Hadley Centre, Exeter.

Kirby K. J., Smart S. M., Black H. I. J., Bunce R. G. H., Corney P.M., Smithers R. J. (2005): Long term ecological change in British woodland (1971-2001): A resurvey and analysis of change based on the 103 sites in the Nature Conservancy 'Bunce 1971' woodland survey. Research Report 653. English Nature, Peterborough.

Lambers H., Chapin F. S., Pons T. L. (1998): Plant Physiological Ecology. SpringerVerlag New York.

Loustau D., Ogee J., Dufréne E., Déqué M., Dupouey J. L., Vadeau V., Vivoy N., Ciais P., Desprez-Loustau M. L., Roques A., Chuine I., Mouillot F. (2007): Impacts of climate change on temperate forests and interaction with management. In: Freer-Smith, P. H., Broadmeadow, M. S. J. and Lynch, J. M. (eds.). Forestry and Climate Change. CABI International, Wallingford, UK.

Murphy J. M., Sexton D. M. H., Jenkins G. J., Boorman P. M., Booth B. B. B., Brown C. C., Clark R. T., Collins M., Harris G. R., Kendon E .J., Betts R. A., Brown S. J., Howard T. P., Humphrey K. A., McCarthy M. P., McDonald R. E., Stephens A., Wallace C., Warren R., Wilby R., Wood R. A. (2009): UK Climate Projections Science Report: Climate change projections. Met Office Hadley Centre, Exeter.

Nielsen C. N., Jorgensen F. V. (2003): Phenology and diameter increment in seedlings of European beech (FagussylvaticaL.) as affected by different soil water contents: variation between and within provenances. Forest Ecology and Management 174, 233-249

Ogaya R., Penuelas J. (2007): Tree growth, mortality, and above-ground biomass accumulation in a holm oak forest under a five-year experimental field drought. Plant Ecology, Vol. 189, 291-299.

Read D. J., Freer-Smith P. H., Morison J. I. L., Hanley N., West C.C., Snowdon P. (eds). (2009): Combating climate change - a role for UK forests. An assessment of the potential of the UK's trees and woodlands to mitigate and adapt to climate change. The Stationery Office, Edinburgh.

Roger M. R. R. (ed.) (2001): Handbook of Plant Ecophysiology Techniques. Kluwer 
Academic Publishers, The Netherlands.

Sanchez-Gomez D., Valladares F., Zavala M.A. (2006): Performance of seedlings of mediterranean woody species under experimental gradients of irradiance and water availability: trade-offs and evidence for niche differentiation. New Phytologist 170, 795-806.

Schwarz C. J. (2011): Sampling, Regression, Experimental Design and Analysis for Environmental Scientists, Biologists, and Resource Managers. Department of Statistics and Actuarial Science, Simon Fraser University.

Tognetti R., Johnson J. D., Michelozzi M. (1995): The response of European beech (Fagussylvatica L.) seedlings from two Italian populations to drought and recovery. Trees 9, 348-354.

Westgarth-Smith A. R., Leroy S. A. G., Collins P. E. F., Harrington R. (2007): Temporalvariations in English populations of a forest insect pest, the green spruce aphid (Elatobiumabietinum), associated with the North Atlantic Oscillation and global warming. Quaternary International 173-174, 153-160. 